\title{
Two-Step Iteration Scheme for Nonexpansive Mappings in Banach Space
}

\author{
M.R. YADAV
}

\begin{abstract}
In this paper, we introduce a new two-step iteration process to approximate common fixed points of two nonexpansive mappings in Banach spaces and established strong and weak convergence results of this iterative scheme. We also shows that our iteration process converges faster than of Mann, S-iterative and modified Ishikawa processes. Our result also illustrated with help of an example with numerical calculation. The results obtained in this paper is generalizations of Sahu [7].
\end{abstract}

\section{INTRODUCTION}

Let $K$ be a nonempty, closed, convex subset of a Banach space $E$. Throughout this paper, $\mathbb{N}$ denotes the set of all positive integers and $F(T) \neq \phi$ i.e., $F(T)=\{x \in K: T x=x\}$. A mapping $T: K \rightarrow K$ is said to be nonexpansive if

$$
\|T x-T y\| \leq\|x-y\|,
$$

for all $x, y \in K$. We know that a point $x \in K$ is a fixed point of $T$ if $T x=x$.

The Mann [5] iteration schemes for a mapping $T: K \rightarrow K$ are defined by

$$
\left\{\begin{aligned}
u_{1} & =u_{0} \in K, \\
u_{n+1} & =\left(1-\alpha_{n}\right) u_{n}+\alpha_{n} T u_{n}, \quad n \in \mathbb{N},
\end{aligned}\right.
$$

where $\left\{\alpha_{n}\right\}$ is in $(0,1)$.

In 1986, Das and Debata [2] generalized Mann and Ishikawa iteration process of two self mappings $S$ and $T$ as follows:

$$
\left\{\begin{aligned}
s_{1} & =s_{0} \in K, \\
s_{n+1} & =\left(1-\alpha_{n}\right) s_{n}+\alpha_{n} S t_{n}, \\
t_{n} & =\left(1-\beta_{n}\right) s_{n}+\beta_{n} T s_{n}, \quad n \in \mathbb{N},
\end{aligned}\right.
$$

where $\left\{\alpha_{n}\right\}$ and $\left\{\beta_{n}\right\} \in(0,1)$.

They used this iteration process to find common fixed points of quasinonexpansive mappings in a uniformly convex Banach space. Takahashi and

2010 Mathematics Subject Classification. Primary: 47H05, 47H10; Secondary: 47H17.

Key words and phrases. Two-step iteration process, Nonexpansive mappings, Condition (A'), Opial's condition, Common fixed point. 
Tamura [9] studied it for the case of two nonexpansive mappings under different conditions in a strictly convex Banach space. For the case of two asymptotically nonexpansive mappings, we refer to Khan and Takahashi [4].

Recently, Sahu [7] introduced the S-iterative process, which has been studied extensively in connection with fixed points of pseudo-contractive mappings as follows.

Let $K$ be a nonempty convex subset of a normed space $X$ and let $T: K \rightarrow K$ be a mapping. Then, for arbitrary $x_{1} \in K$, the $S$-iterative process is defined by

$$
\left\{\begin{aligned}
v_{1} & =v_{0} \in K, \\
v_{n+1} & =T w_{n}, \\
w_{n} & =\left(1-\beta_{n}\right) v_{n}+\beta_{n} T v_{n}, \quad n \in \mathbb{N},
\end{aligned}\right.
$$

where $\left\{\beta_{n}\right\} \in(0,1)$.

In this article, motivated and inspired by the work of Sahu [7], we have introduced a new iterative process (named as Y-iteration). Our iterative process is given below:

$$
\left\{\begin{aligned}
x_{1} & =x_{0} \in K, \\
x_{n+1} & =T y_{n}, \\
y_{n} & =\left(1-\beta_{n}\right) T x_{n}+\beta_{n} S x_{n}, \quad n \geq 1,
\end{aligned}\right.
$$

where $\left\{\beta_{n}\right\} \in[0,1]$.

\section{Preliminaries}

Let $X=\{x \in E:\|x\|=1\}$ and $E^{*}$ be the dual of $E$. The space $E$ has : (i) Gâteaux differentiable norm if

$$
\lim _{t \rightarrow 0} \frac{\|x+t y\|-\|x\|}{t},
$$

exists for each $x, y \in K$;

(ii) Frèchet differentiable norm (see e.g. [9]) for each $x$ in $S$, the above limit exists and is attained uniformly for $y$ in $S$ and in this case, it is also well-known that

$$
\langle h, J(x)\rangle+\frac{1}{2}\|x\|^{2} \leq \frac{1}{2}\|x+h\|^{2} \leq\langle h, J(x)\rangle+\frac{1}{2}\|x\|^{2}+b(\|h\|)
$$

for all $x, h \in E$, where $J$ is the Frèchet derivative of the function $\frac{1}{2}\|\cdot\|^{2}$ at $x \in E,\langle.,$.$\rangle is the dual pairing between E$ and $E^{*}$, and $b$ is an increasing function defined on $[0, \infty)$ such that $\lim _{t \rightarrow 0} \frac{b(t)}{t}=0$;

(iii) Opial's condition [6] if for any sequence $\left\{x_{n}\right\}$ in $E, x_{n} \rightarrow x$ implies that

$$
\limsup _{n \rightarrow \infty}\left\|x_{n}-x\right\|<\limsup _{n \rightarrow \infty}\left\|x_{n}-y\right\|,
$$


for all $y \in E$ with $y \neq x$.

The following definition and lemma which will be useful in proving our main results.

Definition 1. Let $E$ be a Banach space, $K$ be a nonempty closed, convex subset of $E$, and $T: K \rightarrow K$ be a nonexpansive mapping. Then $I-T$ is said to be demi-closed at 0 , if $x_{n} \rightarrow x$ converges weakly and $x_{n}-T x_{n} \rightarrow 0$ converges strongly, then it is implies that $x \in K$ and $T x=x$.

Definition $2([3])$. Suppose two mappings $S, T: K \rightarrow K$, where $K$ is a subset of a normed space $E$, said to be satisfy condition $\left(A^{\prime}\right)$ if there exists a nondecreasing function $F:[0, \infty) \rightarrow[0, \infty)$ with $F(0)=0, f(r)>0$ for all $r \in(0, \infty)$ such that either $\|x-S x\| \geq f(d(x, F))$ or $\|x-T x\| \geq f(d(x, F))$ for all $x \in K$ where $d(x, F)=\inf \{\|x-p\|: p \in F=F(S) \cap F(T)\}$.

Definition 3. A self-mapping $T$ of a subset $K$ of a normed linear space is said to be quasi-nonexpansive provided $T$ has at least one fixed point in $K$, and if $p \in K$ is any fixed point of $T$, then

$$
\|T x-p\| \leq\|x-p\|
$$

holds for all $x \in K$.

Definition 4 ([1]). Assume that $\left\{a_{n}\right\}_{n} \in N$ and $\left\{b_{n}\right\}_{n} \in N$ are two real convergent sequences with limits $a$ and $b$, respectively. Then $\left\{a_{n}\right\}_{n} \in N$ is said to converge faster than $\left\{b_{n}\right\}_{n} \in N$ if

$$
\lim _{n \rightarrow \infty}\left|\frac{a_{n}-a}{b_{n}-b}\right|=0 \text {. }
$$

Lemma 1 ([8]). Suppose that $E$ be a Banach space and $0<p \leq t_{n} \leq$ $q<1$ for all $n \in \mathbb{N}$. Let $\left\{x_{n}\right\}$ and $\left\{y_{n}\right\}$ be two sequences of $E$ such that $\limsup _{n \rightarrow \infty}\left\|x_{n}\right\| \leq r$, limsup $_{n \rightarrow \infty}\left\|y_{n}\right\| \leq r$ and $\lim _{n \rightarrow \infty} \|\left(1-t_{n}\right) x_{n}+$ $t_{n} y_{n} \|=r$ hold for some $r \geq 0$. Then $\lim _{n \rightarrow \infty}\left\|x_{n}-y_{n}\right\|=0$.

\section{Convergence Results}

In this section, we prove the approximate common fixed points of twononexpansive mappings for weak and strong convergence results, using a new type of two-step iteration process. In the consequence, $F$ denotes the set of common fixed point of the mapping $S$ and $T$.

Lemma 2. Let $K$ be a nonempty, closed, convex subset of a Banach space E. Suppose $S, T: K \rightarrow K$ be an nonexpansive mappings and $\left\{x_{n}\right\}$ be the sequence as defined by (4), with restrictions $\sum_{n=1}^{\infty} \beta_{n}<\infty$. If $F(S) \cap F(T) \neq$ $\phi$, and

$$
\|x-S x\| \leq\|T x-S x\|, \quad \text { for all } x, y \in K,
$$


is satisfied, then

$$
\lim _{n \rightarrow \infty}\left\|T x_{n}-x_{n}\right\|=0=\lim _{n \rightarrow \infty}\left\|S x_{n}-x_{n}\right\|,
$$

for all $p \in F(S) \cap F(T)$.

Proof. Suppose $p \in F(S) \cap F(T)$ and $F(S) \cap F(T) \neq \phi$. Since $S, T$ are nonexpansive mappings, now using (4), we have

$$
\left\|x_{n+1}-p\right\|=\left\|T y_{n}-p\right\| \leq\left\|y_{n}-p\right\|
$$

and,

$$
\begin{aligned}
\left\|y_{n}-p\right\| & =\left\|\left(1-\beta_{n}\right) T x_{n}+\beta_{n} S x_{n}-p\right\| \\
& \leq\left(1-\beta_{n}\right)\left\|T x_{n}-p\right\|+\beta_{n}\left\|S x_{n}-p\right\| \\
& \leq\left(1-\beta_{n}\right)\left\|x_{n}-p\right\|+\beta_{n}\left\|y_{n}-p\right\| \\
& \leq\left\|x_{n}-p\right\| .
\end{aligned}
$$

Combining the estimates in (8) and (9), we have

$$
\left\|x_{n+1}-p\right\| \leq\left\|x_{n}-p\right\|
$$

Since $\left\{\left\|x_{n}-p\right\|\right\}$ is a non-increasing and bounded sequence, we get that $\lim _{n \rightarrow \infty}\left\|x_{n}-q\right\|$ exists. Assume that $\lim _{n \rightarrow \infty}\left\|x_{n}-p\right\|=r$. Then if $r=0$, we are done. Suppose that $r>0$. Next, we show that $\lim _{n=t o \infty}\left\|T x_{n}-x_{n}\right\|=0$. Now, taking limsup on both sides of the inequality (9), we have

$$
\left\|y_{n}-p\right\| \leq \limsup _{n \rightarrow \infty}\left\|x_{n}-p\right\| \leq r
$$

Moreover, $r=\lim _{n \rightarrow \infty}\left\|x_{n+1}-p\right\|$ means that

$$
r=\left\|x_{n+1}-p\right\|=\left\|T y_{n}-p\right\| \leq\left\|y_{n}-p\right\| .
$$

Taking liminf on both sides of the above inequality, we get

$$
r \leq \liminf _{n \rightarrow \infty}\left\|y_{n}-p\right\| \text {. }
$$

Combining the estimates in (11) and (12), we have

$$
\lim _{n \rightarrow \infty}\left\|y_{n}-p\right\|=r \text {. }
$$

Next, consider,

$$
\begin{aligned}
r=\left\|y_{n}-p\right\| & =\left\|\left(1-\beta_{n}\right) T x_{n}+\beta_{n} S x_{n}-p\right\| \\
& \leq\left(1-\beta_{n}\right)\left\|T x_{n}-p\right\|+\beta_{n}\left\|S x_{n}-p\right\| .
\end{aligned}
$$

Applying Lemma 1, we have

$$
\lim _{n \rightarrow \infty}\left\|T x_{n}-S x_{n}\right\|=0 .
$$


Using (7) and (14), it follows then that

$$
\begin{aligned}
\left\|T x_{n}-x_{n}\right\| & =\left\|T x_{n}-S x_{n}\right\|+\left\|S x_{n}-x_{n}\right\| \\
& \leq\left\|T x_{n}-S x_{n}\right\|+\left\|T x_{n}-S x_{n}\right\| \\
& \leq 2\left\|T x_{n}-S x_{n}\right\| \\
& \rightarrow 0 \text { as } n \rightarrow \infty .
\end{aligned}
$$

Taking lim as $n \rightarrow \infty$ on both sides of the above inequality, we obtain

$$
\lim _{n \rightarrow \infty}\left\|T x_{n}-x_{n}\right\|=0 .
$$

Again, we observe that for each $n \in \mathbb{N}$,

$$
\left\|S x_{n}-x_{n}\right\| \leq\left\|S x_{n}-T x_{n}\right\|+\left\|T x_{n}-x_{n}\right\| \rightarrow 0 \text { as } n \rightarrow \infty .
$$

which implies that

$$
\lim _{n \rightarrow \infty}\left\|S x_{n}-x_{n}\right\|=0 .
$$

This completes the proof.

Example 1. Let us define $S, T: R \rightarrow R$ define by :

$$
T x=\frac{3-x}{2}
$$

and

$$
S x=\frac{1+4 x}{5}
$$

for all $x \in K$. Obviously both $S$ and $T$ are nonexpansive with the common fixed point 1 for all $x \in R$. Now we check that our condition, $\|x-S x\| \leq$ $\|T x-S x\|$ for all $x \in R$ is true. Then

$$
\begin{aligned}
|x-S x| & =\left|x-\frac{(1+4 x)}{5}\right|=\left|\frac{5 x-1-4 x}{5}\right|=\left|\frac{(1-x)}{5}\right|=\frac{1}{5}|(1-x)|, \\
|T x-S x| & =\left|\frac{3-x}{2}-\frac{1+4 x}{5}\right|=\left|\frac{(15-5 x-2-8 x)}{10}\right| \\
& =\left|\frac{13(1-x)}{10}\right|=\frac{13}{10}|(1-x)| .
\end{aligned}
$$

Hence $\|x-S x\| \leq\|T x-S x\|$, so we can easily show that $S$ and $T$ are nonexpansive mappings.

Lemma 3. Let $K$ be a nonempty, closed, convex subset of a Banach space $E$. Suppose $\left\{x_{n}\right\}$ be the sequence defined in Theorem (1) with $F \neq \phi$. Then, for any $p_{1}, p_{2} \in F, \lim _{n \rightarrow \infty}\left\langle x_{n}, J\left(p_{1}-p_{2}\right)\right\rangle$ exist, in particular, $\left\langle p-q, J\left(p_{1}-\right.\right.$ $\left.\left.p_{2}\right)\right\rangle=0$ for all $p, q \in \omega_{\omega}\left(x_{n}\right)$. 
Proof. Take $x=p_{1}-p_{2}$, with $p_{1} \neq p_{2}$ and $h=t\left(x_{n}-p_{1}\right)$ in the inequality (5) to get:

$$
\begin{aligned}
\frac{1}{2}\left\|p_{1}-p_{2}\right\|^{2}+t\left\langle x_{n}-p_{1}, J\left(p_{1}-p_{2}\right)\right\rangle \leq & \frac{1}{2}\left\|t x_{n}+(1-t) p_{1}-p_{2}\right\|^{2} \\
\leq & \frac{1}{2}\left\|p_{1}-p_{2}\right\|^{2}+t\left\langle x_{n}-p_{1}, J\left(p_{1}-p_{2}\right)\right\rangle \\
& +b\left(t\left\|x_{n}-p_{1}\right\|\right) .
\end{aligned}
$$

As $\sup _{n \geq 1}\left\|x_{n}-p_{1}\right\| \leq M^{\prime}$ for some $M^{\prime}>0$, it follows that

$$
\begin{aligned}
\frac{1}{2}\left\|p_{1}-p_{2}\right\|^{2}+t & \limsup _{n \rightarrow \infty}\left\langle x_{n}-p_{1}, J\left(p_{1}-p_{2}\right)\right\rangle \\
\leq & \frac{1}{2} \lim _{n \rightarrow \infty}\left\|t x_{n}+(1-t) p_{1}-p_{2}\right\|^{2} \\
& \leq \frac{1}{2}\left\|p_{1}-p_{2}\right\|^{2}+b\left(t M^{\prime}\right)+t \liminf _{n \rightarrow \infty}\left\langle x_{n}-p_{1}, J\left(p_{1}-p_{2}\right)\right\rangle .
\end{aligned}
$$

That is,

$$
\limsup _{n \rightarrow \infty}\left\langle x_{n}-p_{1}, J\left(p_{1}-p_{2}\right)\right\rangle \leq \liminf _{n \rightarrow \infty}\left\langle x_{n}-p_{1}, J\left(p_{1}-p_{2}\right)\right\rangle+\frac{b\left(t M^{\prime}\right)}{t M^{\prime}} M^{\prime} .
$$

If $t \rightarrow 0$, then $\lim _{n \rightarrow \infty}\left\langle x_{n}-p_{1}, J\left(p_{1}-p_{2}\right)\right\rangle$ exists for all $p_{1}, p_{2} \in F$, in particular, we get

$$
\left\langle p-1, J\left(p_{1}-p_{2}\right)\right\rangle=0
$$

for all $p, q \in \omega_{\omega}\left(x_{n}\right)$.

Theorem 1. Let $E$ be a Banach space satisfying Opial condition and $K, T, S$ and $\left\{x_{n}\right\}$ be taken as Lemma 2. If $F(S) \cap F(T) \neq \phi, I-T$ and $I-S$ are demiclosded at zero, then $\left\{x_{n}\right\}$ converges weakly to a common fixed point of $S$ and $T$.

Proof. Let $p \in F(S) \cap F(T)$, then as proved in Lemma $2 \lim _{n \rightarrow \infty}\left\|x_{n}-p\right\|$ exist. Since $E$ is Banach space. Thus there exists subsequences $\left\{x_{n_{k}}\right\} \subset$ $\left\{x_{n}\right\}$ such that $\left\{x_{n_{k}}\right\}$ converges weakly to $z_{1} \in K$. From Lemma 2, we have

$$
\lim _{n \rightarrow \infty}\left\|T x_{n_{k}}-x_{n_{k}}\right\|=0
$$

and

$$
\lim _{n \rightarrow \infty}\left\|S x_{n_{k}}-x_{n_{k}}\right\|=0 .
$$

Since $I-T$ and $I-S$ are demiclosed at zero, therefore $S z_{1}=z_{1}$. Similarly $T z_{1}=z_{1}$. Finally, we prove that $\left\{x_{n}\right\}$ converges weakly to $z_{1}$. Let on contrary that there exists a subsequence $\left\{x_{n_{i}}\right\} \subset\left\{x_{n}\right\}$ and $\left\{x_{n_{j}}\right\} \subset\left\{x_{n}\right\}$ such that $\left\{x_{n_{j}}\right\}$ converges weakly to $z_{2} \in K$ and $z_{1} \neq z_{2}$. Again in the same way, we can prove that $z_{2} \in F(S) \cap F(T)$. From Lemma 2 the limits 
$\lim _{n \rightarrow \infty}\left\|x_{n}-z_{1}\right\|$ and $\lim _{n \rightarrow \infty}\left\|x_{n}-z_{2}\right\|$ exists. Suppose that $z_{1} \neq z_{2}$, then by the Opial's condition, we get

$$
\begin{aligned}
\lim _{n \rightarrow \infty}\left\|x_{n}-z_{1}\right\| & =\lim _{n_{i} \rightarrow \infty}\left\|x_{n_{i}}-z_{1}\right\|<\lim _{n_{i} \rightarrow \infty}\left\|x_{n_{i}}-z_{2}\right\| \\
& =\lim _{n \rightarrow \infty}\left\|x_{n}-z_{2}\right\|=\lim _{n_{j} \rightarrow \infty}\left\|x_{n_{j}}-z_{2}\right\| \\
& <\lim _{n_{j} \rightarrow \infty}\left\|x_{n_{j}}-z_{1}\right\|=\lim _{n \rightarrow \infty}\left\|x_{n}-z_{1}\right\| .
\end{aligned}
$$

This is a contradiction so $z_{1}=z_{2}$. Hence $\left\{x_{n}\right\}$ converges weakly to a common fixed point of $T$ and $S$.

Theorem 2. Let $E$ be a Banach space and $K, S, T, F,\left\{x_{n}\right\}$ be as in Lemma 2. Then $\left\{x_{n}\right\}$ converges strongly to a point of $F$ if and only if

$$
\liminf _{n \rightarrow \infty} d\left(x_{n}, F\right)=0 .
$$

Proof. Necessity is evident, let $\lim i n f_{n \rightarrow \infty} d\left(x_{n}, F\right)=0$. From Lemma 2,

$$
\lim _{n \rightarrow \infty}\left\|x_{n}-p\right\|
$$

exists for all $p \in F$, so that $\lim _{n \rightarrow \infty} d\left(x_{n}, F\right)$ exists. Since by hypothesis,

$$
\liminf _{n \rightarrow \infty} d\left(x_{n}, F\right)=0,
$$

so that, we get

$$
\lim _{n \rightarrow \infty} d\left(x_{n}, F\right)=0 .
$$

But $\left\{x_{n}\right\}$ is Cauchy sequence and therefore converges to $p$. We know that

$$
\lim _{n \rightarrow \infty} d\left(x_{n}, F\right)=0,
$$

we obtained $d(p, F)=0$, therefore $p \in F$.

Using Theorem 2, we obtain a strong convergence theorem of the iteration scheme (4) under the condition $\left(A^{\prime}\right)$ as below:

Theorem 3. Let $E$ be a Banach space and $K, S, T, F,\left\{x_{n}\right\}$ be as in Lemma 2. Let $S, T$ satisfy the condition $\left(A^{\prime}\right)$ and $F \neq \phi$. Then $\left\{x_{n}\right\}$ converges strongly to a point of $F$.

Proof. We proved in Lemma 2, i.e.

$$
\lim _{n \rightarrow \infty}\left\|S x_{n}-x_{n}\right\|=0=\lim _{n \rightarrow \infty}\left\|T x_{n}-x_{n}\right\|
$$

Then from the definition of condition $\left(A^{\prime}\right)$, we obtain

$$
\lim _{n \rightarrow \infty} f\left(d\left(x_{n}, F\right)\right) \leq \lim _{n \rightarrow \infty}\left\|T x_{n}-x_{n}\right\|=0
$$

or

$$
\lim _{n \rightarrow \infty} f\left(d\left(x_{n}, F\right)\right) \leq \lim _{n \rightarrow \infty}\left\|S x_{n}-x_{n}\right\|=0 .
$$


In above cases, we get

$$
\lim _{n \rightarrow \infty} f\left(d\left(x_{n}, F\right)\right)=0 .
$$

But $f:[0, \infty) \rightarrow[0, \infty)$ is a nondecreasing function satisfying $f(0)=$ $0, f(r)>0$ for all $r \in(0, \infty)$, so that we get $\lim _{n \rightarrow \infty} d\left(x_{n}, F\right)=0$.

All the conditions of Theorem 2 are satisfied, therefore by its conclusion $\left\{x_{n}\right\}$ converges to strongly to a fixed point of $F$.

The following result is immediate sequel of our strong convergence theorem.

Corollary 1. Let $K$ be a nonempty closed convex subset of a Banach space $E$. Suppose $T$ be a nonexpansive mapping of $K$. Let $\left\{x_{n}\right\}$ be defined by the iteration (3), where $\left\{\alpha_{n}\right\}$ and $\left\{\beta_{n}\right\}$ in $[0,1]$ for all $n \in \mathbb{N}$, then $\left\{x_{n}\right\}$ converges strongly to a fixed point of $T$.

Example 2. Let $K$ be a nonempty, closed, convex subset of a Banach space $E$. Suppose $S, T: K \rightarrow K$ be an nonexpansive mappings and each of the iterative processes (1), (2) and (3), converges to the same fixed point $p$ of $T$ where $\left\{\alpha_{n}\right\}$ and $\left\{\beta_{n}\right\}$ are such that $0<\delta \leq \alpha_{n}, \beta_{n}<1$, for all $n \in \mathbb{N}$ and for some $\delta$ with $\lim _{n \rightarrow \infty} \alpha_{n}=0=\lim _{n \rightarrow \infty} \beta_{n}$. Then the iterative process given by (4) converges faster than all the other three processes.

Proof. Suppose $p$ be a fixed point of $T$. Then from Mann iterative process (1), we obtain

$$
\begin{aligned}
\left\|u_{n+1}-p\right\| & =\left\|\left(1-\alpha_{n}\right)\left(u_{n}-p\right)+\alpha_{n}\left(T u_{n}-p\right)\right\| \\
& \leq\left(1-\alpha_{n}\right)\left\|u_{n}-p\right\|+\alpha_{n}\left\|T u_{n}-p\right\| \\
& \leq\left(1-\alpha_{n}\right)\left\|u_{n}-p\right\|+\alpha_{n} \delta\left\|u_{n}-p\right\| \\
& =\left[1-\alpha_{n}(1-\delta)\right]\left\|u_{n}-p\right\| \\
& \vdots \\
& \leq\left[1-\alpha_{n}(1-\delta)\right]^{n}\left\|u_{1}-p\right\| .
\end{aligned}
$$

Assume that $a_{n}=\left(1-\alpha_{n}(1-\delta)\right)^{n}\left\|u_{1}-p\right\|$.

Modified Ishikawa iterative process (2) gives

$$
\begin{aligned}
\left\|s_{n+1}-p\right\| & =\left\|\left(1-\alpha_{n}\right)\left(s_{n}-p\right)+\alpha_{n}\left(S t_{n}-p\right)\right\| \\
& \leq\left(1-\alpha_{n}\right)\left\|s_{n}-p\right\|+\alpha_{n}\left\|S t_{n}-p\right\| \\
& \leq\left(1-\alpha_{n}\right)\left\|s_{n}-p\right\|+\alpha_{n} \delta\left\|t_{n}-p\right\| \\
& \leq\left(1-\alpha_{n}\right)\left\|s_{n}-p\right\|+\alpha_{n} \delta\left[\left\|\left(1-\beta_{n}\right) s_{n}+\beta_{n} T s_{n}-p\right\|\right] \\
& =\left(1-\alpha_{n}\right)\left\|s_{n}-p\right\|+\alpha_{n} \delta\left[\left(1-\beta_{n}\right)\left\|s_{n}-p\right\|+\beta_{n}\left\|T s_{n}-p\right\|\right] \\
& \leq\left(1-\alpha_{n}\right)\left\|s_{n}-p\right\|+\alpha_{n} \delta\left[\left(1-\beta_{n}\right)\left\|s_{n}-p\right\|+\beta_{n} \delta\left\|s_{n}-p\right\|\right]
\end{aligned}
$$




$$
\begin{aligned}
& =\left[1-\alpha_{n}(1-\delta)\left(1-\beta_{n}\right)\right]\left\|s_{n}-p\right\| \\
& \vdots \\
& \leq\left[1-\alpha_{n}(1-\delta)\left(1-\beta_{n}\right)\right]^{n}\left\|s_{1}-p\right\| .
\end{aligned}
$$

Assume that $b_{n}=\left[1-\alpha_{n}(1-\delta)\left(1-\beta_{n}\right)\right]^{n}\left\|s_{1}-p\right\|$.

By S-iterative process (3), we have

$$
\begin{aligned}
\left\|v_{n+1}-p\right\| & =\left\|T w_{n}-p\right\| \\
& \leq \delta\left\|w_{n}-p\right\| \\
& =\delta\left[\left\|\left(1-\beta_{n}\right)\left(v_{n}-p\right)+\beta_{n}\left(T v_{n}-p\right)\right\|\right] \\
& \leq \delta\left[\left(1-\beta_{n}\right)\left\|v_{n}-p\right\|+\beta_{n}\left\|T v_{n}-p\right\|\right] \\
& =\delta\left[\left(1-\beta_{n}\right)\left\|v_{n}-p\right\|+\beta_{n} \delta\left\|v_{n}-p\right\|\right] \\
& =\delta\left[\left(1-\beta_{n}(1-\delta)\right)\right]\left\|v_{n}-p\right\| \\
& \vdots \\
& \leq \delta^{n}\left[\left(1-\alpha_{n}(1-\delta)\right)^{n}\right]\left\|u_{1}-p\right\| .
\end{aligned}
$$

Let $c_{n}=\delta^{n}\left[\left(1-\alpha_{n}(1-\delta)\right)^{n}\right]\left\|u_{1}-p\right\|$.

Our process (4) gives

$$
\begin{aligned}
\left\|x_{n+1}-p\right\| & =\left\|T y_{n}-p\right\| \\
& \leq \delta\left\|y_{n}-p\right\| \\
& =\delta\left[\left\|\left(1-\beta_{n}\right)\left(T x_{n}-p\right)+\beta_{n}\left(S x_{n}-p\right)\right\|\right] \\
& \leq \delta\left[\left(1-\beta_{n}\right)\left\|T x_{n}-p\right\|+\beta_{n}\left\|S x_{n}-p\right\|\right] \\
& \leq \delta\left[\left(1-\beta_{n}\right) \delta\left\|x_{n}-p\right\|+\beta_{n} \delta\left\|x_{n}-p\right\|\right] \\
& =\delta^{2}\left\|x_{n}-p\right\| \\
& \vdots \\
& \leq \delta^{2 n}\left\|x_{1}-p\right\| .
\end{aligned}
$$

Let $d_{n}=\delta^{2 n}\left\|x_{1}-p\right\|$.

Now $\lim _{n \rightarrow \infty} \frac{d_{n}}{a_{n}}=\lim _{n \rightarrow \infty} \frac{\delta^{2 n}\left\|x_{1}-p\right\|}{\left(1-\alpha_{n}(1-\delta)\right)^{n}\left\|u_{1}-p\right\|}=\lim _{n \rightarrow \infty} \frac{\delta^{2 n}}{\left(1-\alpha_{n}(1-\delta)^{n}\right.} \times \lim _{n \rightarrow \infty} \frac{\left\|x_{1}-p\right\|}{\left\|u_{1}-p\right\|}$, since $\lim _{n \rightarrow \infty} \delta_{n}=0$ and $\alpha_{n}<1$ so that $\lim _{n \rightarrow \infty} \frac{d_{n}}{a_{n}}=0$. Thus $\left\{x_{n}\right\}$ converges faster than $\left\{u_{n}\right\}$ to $p$. It is not difficult to we prove that for the S-iteration process, and hence $\left\{x_{n}\right\}$ converges faster than $\left\{s_{n}\right\}$ and $\left\{v_{n}\right\}$ to $p$. Thus, $\mathrm{Y}$-iteration process converges faster than the Mann, modified Ishikawa and S-iteration process.

We support our above analytical proof by a numerical example.

Example 3. Let $X=R$ and $K=[1, \infty)$. Let $T: K \rightarrow K$ be an operator defined by $T x=\frac{3-x}{2}$ and $S x=\frac{1+4 x}{5}$ for all $x \in K$. It is not difficult to 
show that $\mathrm{T}$ is a contraction. Choose $\alpha=0.5$ and $\beta=0.33$ for all $n$ with initial value $x_{1}=30$. The comparison given in the following table shows that Y-iterative process (4) converges faster than all Mann, S-iterative and modified Ishikawa processes up to the accuracy of fourteen decimal places.

\section{TABLE 1. A comparison table of our process with other processes}

\begin{tabular}{|c|c|c|c|c|}
\hline teps & Y-iteration & Mann Iteration & S-iteration & Modified Ishikawa \\
\hline 1. & 1.67450000000000 & 5.75000000000000 & 3.79750000000000 & 6.06350000000000 \\
\hline 2. & 1.023944 & 000 & 2.2113 & 2.34 \\
\hline 3. & 1.000850 & 1.2968 & 0.69412 & 1.35962 \\
\hline 4. & 1.00003017637 & 1.0742 & 1.07723 & 1.095 \\
\hline 5. & 1.000001 & 1.018 & 0.98049 & 4110413500 \\
\hline 6. & 1.000000 & & $1.004 \mathrm{~s}$ & 1.006 \\
\hline 7. & 1.000000 & & & 1.00 \\
\hline 8. & 1.000000 & & & 106 \\
\hline 9. & 1.00 & & & \\
\hline 10. & 1.0 & & & \\
\hline 11. & 1.000 & 1.000 & 0.99 & 1.00000915003906 \\
\hline 12. & 1.00000000000 & 1.00000113248825 & 1.00000 & 1.00000243848541 \\
\hline 13. & & & & 1.00000064985636 \\
\hline 14. & & & & 1.00000017318672 \\
\hline 26. & ......... & 1.00000000000000 & & ..... \\
\hline 27. & & 1.00000000000000 & 1.00000000000 & \\
\hline 28. & & 1.00000000000000 & 1.00000000000000 & 1.00000000000000 \\
\hline
\end{tabular}

\section{CONCLUSION}

In view of below table Y-iteration procedure converges in 11th steps, Mann iteration process in 26th steps, S-iteration process converges 27th steps and modified Ishikawa iteration process converges 28th steps. The above calculations have been repeated by taking different values of parameters $\alpha_{n}$ and $\beta_{n}$. Hence the $\mathrm{Y}$-iteration process converges faster than Mann, Siteration and Modified Ishikawa iteration process to the fixed point 1 of $S$ and $T$. The decreasing rate of convergence of iterative process is as follows : Y-iteration, Mann, S-iteration and modified Ishikawa iterative process.

\section{ACKNOWLEDGMENTS}

The author would like to express their gratitude to the referee for his (or her) valuable comments and suggested that led to a significant improvement of the manuscript and the Editor of Mathematica Moravica for his valuable comments and suggestions that allowed him to improve the original paper. 


\section{REFERENCES}

[1] V. Berinde, Picard iteration converges foster than Mann iteration for a class of quasicontractive operators, Fixed Point Theory and Applications, Vol. 2 (2004), 97-105.

[2] G. Das and J.P.Debata, Fixed points of Quasi-nonexpansive mappings, Indian J. Pure. Appl. Math., Vol. 17 (1986), 1263Ü1269.

[3] H. Fukhar-ud-din, and S.H. Khan, Convergence of iterate with errors of asymptotically quasi-nonexpansive mappings and application, J. Math. Anal. Appl. Vol. 328 (2007), 821-829.

[4] S.H. Khan and W. Takahashi, Approximating common fixed points of two asymptotically nonexpansive mappings, Sci.Math.Japon., Vol. 53, No. 1 (2001), 143-148.

[5] W.R. Mann, Mean value methods in iteration, Proc. Amer. Math. Soc. Vol., 4 (1953), 506-510.

[6] Z. Opial, Weak and convergence of successive approximations for nonexpansive mapping, Bull. Amer. Math. Soc. Vol., 73 (1967), 591-597.

[7] D. R. Sahu, Applications of the S-iteration process to constrained minimization problems and split feasibility problems, Fixed Point Theory, Vol. 12, No. 1 (2011), 187 Ü204.

[8] J. Schu, Weak and strong convergence to fixed points of asymptotically nonexpansive mappings, Bull. Aust. Math. Soc. Vol., 43 (1991), 153-159.

[9] W. Takahashi and T. Tamura, Convergence theorems for a pair of nonexpansive mappings, J. Convex Anal. Vol5, (1995), No. 1, 45-58.

\section{M.R. YADAV}

School of Studies in Mathematics Pt.Ravishankar Shukla University

Raipur, ChHattisgarh-492010

INDIA

E-mail address: yadavmryadav@gmail.com 